\title{
The efficacy of computerized cognitive rehabilitation in improving attention and executive functions in acquired brain injury patients, in acute and postacute phase
}

\author{
Ha Seong KIM 1,2, Kil-Byung LIM 1, Jeehyun YOO 1, Yong Wook KIM 3, \\ Sang Wan LEE ${ }^{1}$, Sungsik SON ${ }^{1}$, Changgyu KIM ${ }^{1}$, Jiyong KIM ${ }^{1}$ *
}

1Department of Physical Medicine and Rehabilitation, Ilsan Paik Hospital, Inje University, Goyang, South Korea; ${ }^{2}$ Yonsei University College of Medicine, Seoul, South Korea; ${ }^{3}$ Department and Research Institute of Rehabilitation Medicine, Yonsei University College of Medicine, Seoul, South Korea

*Corresponding author: Jiyong Kim, Department of Physical Medicine and Rehabilitation, Ilsan Paik Hospital, Inje University, 10380 Goyang, South Korea. E-mail: halwayskim@gmail.com

\section{A B S T R A C T}

BACKGROUND: Cognitive deficits, particularly executive dysfunction is common following acquired brain injury (ABI) and has detrimental effect on functional status and autonomy in daily life. Among various cognitive training methods, computerized cognitive rehabilitation (CCR) has been investigated as an alternative method to therapist-driven cognitive rehabilitation (TCR). However, previous studies have shown conflicting results on the superiority or inferiority of CCR and TCR.

AIM: To investigate the efficacy of TCR and CCR in improving executive function in patients with acute-to-subacute ABI.

DESIGN: A prospective, assessor-blinded randomized controlled trial.

SETTING: Hospitalized care setting in the department of rehabilitation in a university hospital.

POPULATION: Thirty-two acute-to-subacute (less than 3 months after onset) ABI patients with executive dysfunctions were included in this study. The mean time after injury was $25.1 \pm 18.1$ days.

METHODS: Participants were assigned to the TCR group $(\mathrm{N} .=14)$ or the CCR group $(\mathrm{N} .=18)$. Each group performed TCR or CCR for 30 minutes each day for two weeks in addition to routine rehabilitation. Neurocognitive function tests to assess complex attention, executive function, general cognitive function (mini-mental status examination [MMSE] and Montreal Cognitive Assessment [MoCA]), and functional evaluations [modified Barthel Index, MBI]) were performed at baseline (T0) and at the end of treatment (T1).

RESULTS: The TCR and CCR groups showed significant improvements in the MMSE $(\mathrm{P}=0.004,0.000)$, MoCA $(\mathrm{P}=0.003,0.006)$, and MBI $(\mathrm{P}=0.000,0.000)$ scores. TCR and CCR groups both showed significant improvements in some of the complex attention tests (trail-making test $\mathrm{A}, \mathrm{P}=0.002,0.005$ ) and executive function tests (trail-making test $\mathrm{B}, \mathrm{P}=0.016,0.016$ ). The TCR group showed significant improvements in the additional executive function tests (phonemic fluency test, $\mathrm{P}=0.004$, semantic fluency test, $\mathrm{P}=0.001$ ), while the CCR group showed significant improvements in the additional complex attention tests (symbol search, $\mathrm{P}=0.02$, digit symbol coding, $\mathrm{P}=0.002$ ). In the intergroup comparison of the changes from pre- to postintervention, only the TCR group showed a significant improvement in the phonemic fluency test $(\mathrm{P}=0.013)$. CONCLUSIONS: TCR might be more effective than CCR in improving frontal lobe-related executive function in ABI patients. CCR might be beneficial for improving psychomotor speed and working memory.

CLINICAL REHABILITATION IMPACT: TCR or CCR should be chosen according to the targeted domain of cognitive dysfunction in acuteto-subacute $\mathrm{ABI}$ patients.

(Cite this article as: Kim HS, Lim KB, Yoo J, Kim YW, Lee SW, Son S, et al. The efficacy of computerized cognitive rehabilitation in improving attention and executive functions in acquired brain injury patients, in acute and postacute phase. Eur J Phys Rehabil Med 2021;57:551-9. DOI: 10.23736/S1973-9087.21.06497-2)

KEY WORDS: Cognitive disorders; Therapy, computer-assisted; Executive function; Brain injuries.

A cquired brain injury (ABI), which refers to the damage to the brain in nonprogressive nature, includes hemorrhagic stroke, ischemic stroke, and traumatic brain injury and results in a significant burden on the individual and community. ${ }^{1}$ Persistent cognitive deficits are common following ABI, particularly deficits in executive function- 


\section{COPYRIGHT $^{\circledR} 2021$ EDIZIONI MINERVA MEDICA}

ing, attention, and learning. ${ }^{2,3}$ These sequalae, together with other motor dysfunctions following ABI, have a detrimental effect on functional status and may decrease individuals' autonomy in daily life. ${ }^{4}$ Stroke survivors with mild or severe cognitive dysfunction are 3.17 or 12.20 times more likely to have self-care problems and 3.31 or 16.61 times more likely to have problems performing daily activities. ${ }^{5}$ Among the various domains of cognitive function, executive function in particular is considered to be a strong predictor of recovery from disability in patients with acute stroke.4, 6

Executive functions are higher-order cognitive regulatory processes that include inhibitory control, working memory, planning, decision-making, and error correction, which enhance a patient's capacity to problem-solve and sustain goal-oriented exploration. ${ }^{7-9}$ Executive dysfunction hampers individuals' capacity to adapt to diverse situations and prevents them from acquiring independent living skills, thereby preventing their successful community re-entry after ABI. ${ }^{10}$

Therefore, individuals with $\mathrm{ABI}$ may require the restoration of not only basic cognitive function but also executive function to perform complex and adaptive tasks. ${ }^{11} \mathrm{On}$ the other hand, improvement in cognitive impairment after ABI mostly occurs in the first year after onset, ${ }^{12,13}$ and the largest magnitude of improvement occurs within the first 3 months after onset. ${ }^{14}$ Furthermore, it has been stated that the recovery of cognitive functions occurs faster when interactive rehabilitation programs are practiced during the acute or subacute stroke stage. ${ }^{15-17}$ Accordingly, it would be meaningful to investigate the optimal rehabilitative interventions for improving executive function in individuals in the acute-to-subacute phase after ABI.

Approaches to improve cognitive function, via cognitive rehabilitation, in ABI patients have long been researched. Cognitive rehabilitation approaches can generally be divided into two categories, restorative and compensatory approaches. ${ }^{18}$ Restorative approaches aim to strengthen individuals' impaired cognitive function and improve their cognitive ability through repetitive training, while compensatory approaches focus on modifying patients' behavioral patterns and teaching them ways to cope with lost cognitive functioning. ${ }^{19,} 20$

Among the various cognitive training methods, computerized cognitive rehabilitation (CCR) has been investigated as an alternative or supplementary method to therapistdriven cognitive rehabilitation (TCR). Many CCR programs utilized in previous studies are included in restorative approaches composed of repetitive training programs to enhance cognitive function. $10,18,21-23$ Even though the efficacy of CCR by itself in ABI patients has been observed, 3, 21-29 previous studies have shown conflicting results on the superiority or inferiority of CCR and TCR. ${ }^{30,31}$ In addition, a number of previous studies utilizing CCR did not focus on executive function $23,26,29,32$ or did not include an adequate control group for comparison $22,23,25$ or only included patients in the chronic phase. $3,21,23-25,27,32-34$ Thus, we thought that the efficacy of restorative TCR and CCR in improving executive function in acute-to-subacute ABI patient needs to be compared.

Consequently, the aims of this study were to investigate the effectiveness and efficacy of restorative TCR and CCR in improving executive dysfunction and to distinguish the benefits of the two methods in acute-to-subacute ABI patients.

\section{Materials and methods}

\section{Participants}

This study is a prospective, randomized controlled study with an assessor-blinded, two-arm parallel group design using a 1:1 ratio of allocation, in accordance with the CONSORT recommendations. Patients included in this study were the ones with non-coma ABI, including hemorrhagic stroke, ischemic stroke, and traumatic brain injury, who were admitted to the Department of Physical Medicine and Rehabilitation in a university hospital in Korea from August 2018 to March 2020 were included in this study. The patients were randomly assigned to one of two groups (TCR or CCR). An independent researcher used sequentially numbered containers for randomization. Either the patient or a relative of the patient was adequately informed about the study and provided written consent. This study was approved by the relevant institutional review board and research ethics committee (N. 2018-10-007) before experiment began. All methods were performed in accordance with the principles set forth in the Helsinki Declaration, relevant guidelines and regulations.

The inclusion criteria for the participants were as follows: 1) a diagnosis of ABI confirmed by brain imaging studies and clinical data; 2) ABI that developed fewer than 3 months prior; 3 ) the presence of cognitive impairment (Mini-Mental Status Examination [MMSE] score ranging from 10-26 or clinical dementia rating score of more than 0.5 points); 4) the absence of disabling sensory alterations, severe psychiatric and medical illness; and 5) an age older than 18 . 


\section{COPYRIGHT $^{(} 2021$ EDIZIONI MINERVA MEDICA}

The exclusion criteria were as follows: 1) having a severe cognitive comorbidity to participate in an adequate cognitive rehabilitation training (e.g. impaired alertness, sensory aphasia, neglect, amnestic syndrome interfering with treatment); 2) having a medically unstable condition (e.g. pneumonia, cardiovascular diseases); 3) being illiterate; and 4) having had severe cognitive, neurologic, muscular and mechanical problems before the onset of ABI.

\section{Instrumentation}

In the present study, the CCR software used was RehaCom (Hasomed GmbH; Magdeburg, Germany), which is a comprehensive program that uses computer systems for cognitive training. RehaCom includes a number of therapeutic modules that activate and stimulate specific cognitive domains: complex attention, working memory, visuomotor abilities, visual field, and other executive functionings. ${ }^{35}$ The modules for each domain have different levels of complexity that can be automatically adjusted in response to whether the subject succeeds or fails in a given task.23 The computer also gives the subjects auditory instructions and feedback on their performance in their own language. In each module, the number of errors and test completion time for each patient are recorded; the records can be reviewed at every successive training session as a reference value for planning further training.

\section{Intervention}

Comprehensive rehabilitation, including physical therapy and occupational therapy, for physical disabilities other than cognitive dysfunction was performed on the patients in both groups in the same manner with the same dose; 60 minutes of physical therapy and 30 minutes of occupational therapy were performed 5 days a week for 2 weeks. The physical and occupational therapy sessions were composed of various treatment approaches; biomechanical and neurophysiological approach, task-oriented training, strengthening exercise, and motor relearning for physical therapy; range of motion exercise, gross motor and fine motor exercise, and activities of daily living (ADL) training for occupational therapy. ${ }^{36-38}$

For the TCR group, in addition to routine rehabilitation, 30 minutes of cognitive training with a restorative approach was performed daily. The treatment was administered by 3 occupational therapists who were qualified in performing adequate cognitive rehabilitation. The therapeutic session was composed of manual tabletop activities that were designed to improve multiple neurocogni- tive domains including attention and executive functions. The therapists were allowed to intervene initiatively to any extent during the session in accordance with occupational and cognitive remediation principles and theories. $39-42$

For the CCR group, on the other hand, an additional 30 minutes of cognitive training using RehaCom was performed daily. Among the various training modules, we chose to focus on several specific modules that were closely related to the following domains of complex attention and executive functioning: divided attention, working memory, calculation and planning. One of three trained therapists was randomly assigned to supervise each patient. For every patient, the first time each module was performed, the therapist provided instructions on the training procedure. Afterwards, the therapist intervened only when the patient was unable to complete the module in an appropriate way and corrected only the technical or procedural aspects to maximize the role of CCR. The therapist took into account the information recorded from past sessions and gradually adjust the difficulty of the modules accordingly as the treatment progressed.

These additional TCR and CCR sessions for each group were performed 5 times a week for 2 weeks.

\section{Outcome measures}

Cognitive function was assessed in both groups at the time of enrollment (T0) and at the end of the 2 weeks of treatment sessions (T1) by the same experienced psychologist who was blinded to group allocation. Functional performance in ADL was assessed by occupational therapists who were also blinded to group allocation.

To assess cognitive dysfunctions according to various neurocognitive domains, we utilized the following assessment tools. We used subtests included in the third edition of the Wechsler Adult Intelligence Scale; working memory index tests, including the digit span forward and backward (DSF, DSB, respectively) tests; and processing speed indexes, including the digit symbol coding (DSC) and symbol searching (SS) tests. In addition, the following specific tests were also included; the trail making test $\mathrm{A}$ and $\mathrm{B}$ (TMT-A, TMT-B, respectively) and controlled oral word association test (COWAT). To specify the utilities of each used measurement tools, DSF and DSB measure immediate and sustained verbal working memory; DSC, SS, and TMT-A measure complex attention (processing speed and selective attention); TMT-B and DSB measure executive function (mental flexibility and executive control of attention). ${ }^{43-46}$ The COWAT was used to assess the efficiency of 


\section{COPYRIGHT $^{(} 2021$ EDIZIONI MINERVA MEDICA}

retrieval strategies, self-monitoring and inhibition of inappropriate responses. The COWAT is composed of the phonemic (letter) fluency test (PFT) and semantic (category) fluency test (SFT) and is widely used to assess frontal and temporal lobe executive dysfunction. ${ }^{47,}, 48$ When undergoing the PFT or SFT, the subject is asked to name as many items as possible under a time constraint of 1 minute. In the PFT, the subject is asked to name words with specific initial letters in sequence (normally C, F, and L in the English language; "[giyeok]," " [ieung]," and "[siot]" in the Korean language). In the SFT, the subject is asked to name objects in given categories (animals, fruits, and vegetables).

For the assessment of general cognitive function, the total score and subscores of the MMSE and Montreal Cognitive Assessment (MoCA) were recorded. We utilized the MoCA as well as the MMSE because it contains several more items for assessing executive function. ${ }^{49}$ Moreover, MoCA is known to be a more sensitive test in detecting mild cognitive dysfunction and is more indicative of functional impairments in patients with stroke. ${ }^{50}$ The functional performance in ADL was measured by the Modified Barthel Index (MBI) at T0 and T1. The primary outcome measures of this study were the test results of executive function assessment; DSB, TMT-B, and COWAT (PFT and SFT).

\section{Statistical analysis}

The statistical analyses were performed using the Statistical Package for the Social Sciences, version 19 (IBM Corp.; Armonk, NY, USA), for Windows. We compared the demographic and clinical characteristics and initial neuropsychological assessment results between the TCR and CCR group with independent $t$-tests, 2-tailed MannWhitney U tests, $\chi^{2}$ tests, and Fisher's Exact tests, as appropriate. Additionally, as some data were not normally distributed according to Shapiro-Wilk test results, nonparametric tests were also used to evaluate the intragroup and intergroup differences. The paired $t$-tests and Wilcoxon signed-rank test were used to analyze the intragroup changes over time, while the two-tailed Mann-Whitney test was used to compare the intergroup differences in the magnitude of improvement from $\mathrm{T} 0$ to $\mathrm{T} 1$.

\section{Data availability}

The data associated with the paper are not publicly available but are available from the corresponding author on reasonable request.

\section{Results}

Between August 2018 and March 2020, 133 participants with ABI were assessed for eligibility. Ninety-eight participants were excluded because they did not meet the inclusion criteria (severe cognitive impairment $([\mathrm{MMSE}<10]$ $[\mathrm{N} .=50]$ or intact cognitive function $[\mathrm{MMSE}>26][\mathrm{N} .=13]$ ), unwillingness to participate $(\mathrm{N} .=34)$, or medically unstable status $(\mathrm{N} .=1)$. After randomization, there were 3 dropouts because they were discharged early from the hospital. Finally, 14 patients in the TCR group and 18 patients in the CCR group were included. There were no harmful or unintended effects reported during the study (Figure 1).

Thirty-two acute-to-subacute ABI patients with a mean age of $64.7 \pm 15.2$ years (time after onset: $25.1 \pm 18.1$ days) were included. Among the participants, 53.1\% (N.=17) had ischemic stroke; $37.5 \%(\mathrm{~N} .=12)$ had hemorrhagic stroke, including intracerebral hemorrhage and subarachnoid hemorrhage; and the remaining 9.4\% $(\mathrm{N} .=3)$ had traumatic brain injury. There were no statistically significant differences between the two groups in the baseline demographic and clinical characteristics (Table I).

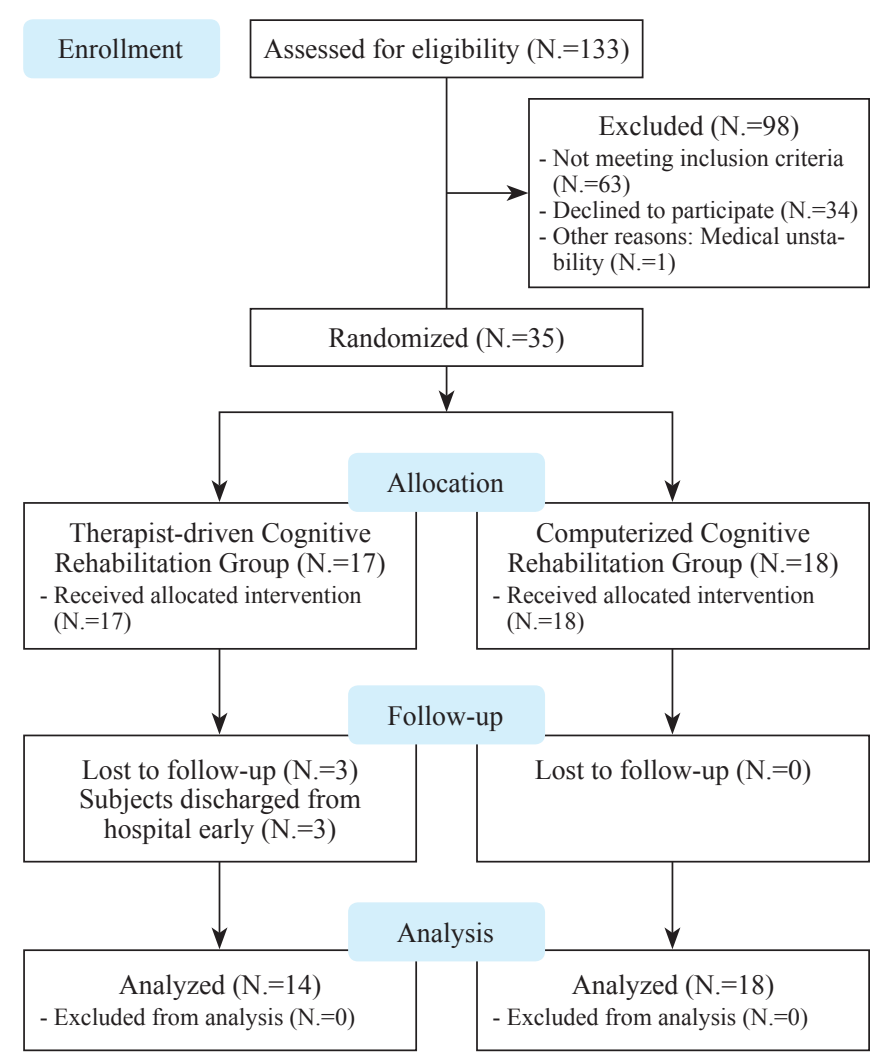

Figure 1.-Flow diagram of the study. 


\section{COPYRIGHT $^{(\odot)} 2021$ EDIZIONI MINERVA MEDICA}

METHODS OF COGNITIVE REHABILITATION

KIM

TABLE I.-Demographic and clinical characteristics of the study participants.

\begin{tabular}{lccc}
\hline Variables & $\begin{array}{c}\text { Therapist- } \\
\text { driven cognitive } \\
\text { rehabilitation group } \\
(\mathrm{N} .=14)\end{array}$ & $\begin{array}{c}\text { Computerized } \\
\text { cognitive } \\
\text { rehabilitation group } \\
(\mathrm{N} .=18)\end{array}$ & $\mathrm{P}$ \\
\hline Age (y) & $62.5 \pm 16.4[19-84]$ & $66.4 \pm 14.4[27-86]$ & 0.488 \\
Education (y) & $10.1 \pm 3.5[6-16]$ & $8.7 \pm 5.2[0-17]$ & 0.536 \\
Sex & $10(71.4)$ & $9(50.0)$ & 0.221 \\
Male & $4(28.6)$ & $9(50.0)$ & \\
Female & & & 0.706 \\
Lesion & $8(57.1)$ & $12(66.7)$ & \\
Right & $5(35.7)$ & $6(33.3)$ & \\
Left & $1(7.1)$ & $0(0.0)$ & \\
Both & $8(57.1)$ & $9(50.0)$ & \\
Type of injury & $4(28.6)$ & $8(44.4)$ & \\
Ischemic stroke & $2(14.3)$ & $1(5.6)$ & \\
Hemorrhagic stroke & $5(35.7)$ & $5(27.8)$ & \\
Traumatic brain injury & $22.9 \pm 14.6[8-60]$ & $26.9 \pm 20.6[8-89]$ & 0.613 \\
Time after injury & $9(64.3)$ & $13(72.2)$ & \\
Acute & $30.0 \pm 16.3[4-56]$ & $30.1 \pm 19.3[0-60]$ & 0.986 \\
Subacute & $22.9 \pm 4.8[15-28]$ & $21.7 \pm 3.9[14-30]$ & 0.462 \\
MBI & $16.3 \pm 6.1[7-24]$ & $15.4 \pm 5.4[7-29]$ & 0.684 \\
MMSE & $1.2 \pm 0.7[0.5-2.0]$ & $1.3 \pm 0.7[0.5-3.0]$ & 0.442 \\
MoCA & $6.1 \pm 4.9[1-13]$ & $5.1 \pm 5.1[0-14]$ & 0.556 \\
CDR & & & \\
GDS & & &
\end{tabular}

Data are given as mean $\pm \mathrm{SD}$ [minimum-maximum value] or N. (\%).

MBI: modified Barthel Index; MMSE: mini-mental status examination; MoCA: Montreal cognitive assessment; CDR: clinical dementia rating; GDS: Geriatric Depression Scale.

The neuropsychological function test results measured at T0 are given in Table II. There were no significant differences in any of the test results at baseline between the two groups.
TABLE II.-Baseline scores of neurocognitive function tests.

\begin{tabular}{lccc}
\hline Variables & $\begin{array}{c}\text { Therapist-driven cognitive } \\
\text { rehabilitation group } \\
(\mathrm{N} .=14)\end{array}$ & $\begin{array}{c}\text { Computerized cognitive } \\
\text { rehabilitation group } \\
(\mathrm{N} .=18)\end{array}$ & $\mathrm{P}$ \\
\hline DSF & $5.2 \pm 1.3$ & $5.6 \pm 1.4$ & 0.416 \\
DSB & $2.9 \pm 1.2$ & $3.1 \pm 1.1$ & 0.750 \\
TMT-A & $119.2 \pm 120.8$ & $120.2 \pm 110.9$ & 0.697 \\
TMT-B & $185.2 \pm 120.7$ & $211.8 \pm 119.8$ & 0.728 \\
SS & $8.6 \pm 9.4$ & $6.2 \pm 7.1$ & 0.570 \\
DSC & $17.2 \pm 17.5$ & $17.2 \pm 19.1$ & 0.860 \\
SFT & $9.6 \pm 4.9$ & $9.2 \pm 6.3$ & 0.442 \\
PFT & $3.3 \pm 3.2$ & $5.0 \pm 4.7$ & 0.249 \\
\hline
\end{tabular}

Data are given as mean \pm SD.

DSF: digit span forward; DSB: digit span backward; TMT-A: trail making test-A; TMT-B: trail making test-B; SS: symbol search; DSC: digit symbol coding; SFT: semantic fluency test; PFT: phonemic fluency test.

In the intragroup comparison between $\mathrm{T} 0$ and $\mathrm{T} 1$, as shown in Table III, the patients in both groups exhibited significantly improved outcomes in the MBI, MMSE, MoCA, TMT-A, and TMT-B scores but not in the DSF, DSB scores. Moreover, only the participants in the TCR group showed significant improvements in the COWAT results (SFT and PFT $[\mathrm{P}=0.001$ and .004 , respectively]), while only the CCR group showed significant improvements in the SS and DSC test results $(\mathrm{P}=0.023$ and .002 , respectively). As shown in Table IV, which presents the mean differences in the outcomes between T1 and T0 for both groups, only the PFT results in the TCR group showed a statistically significant difference in improvement from $\mathrm{T} 0$ to $\mathrm{T} 1(\mathrm{P}=0.013)$. The MBI scores improved by $22.6 \pm 16.6$ and $16.6 \pm 13.4$ in the TCR and CCR groups, respectively $(\mathrm{P}=0.220)$, indicating improvement in functional performance in ADL.

TABLE III.-Test scores of pre- and postintervention with intragroup comparisons.

\begin{tabular}{|c|c|c|c|c|c|c|}
\hline \multirow[t]{2}{*}{ Variables } & \multicolumn{3}{|c|}{$\begin{array}{l}\text { Therapist-driven cognitive rehabilitation group } \\
\qquad(\mathrm{N} .=14)\end{array}$} & \multicolumn{3}{|c|}{$\begin{array}{l}\text { Computerized cognitive rehabilitation group } \\
\qquad(\mathrm{N} .=18)\end{array}$} \\
\hline & Pre & Post & $\mathrm{P}$ & Pre & Post & $\mathrm{P}$ \\
\hline MBI & $30.0 \pm 16.3$ & $52.6 \pm 17.1$ & $<0.001 * * *$ & $30.1 \pm 19.3$ & $46.7 \pm 19.4$ & $<0.001 * * *$ \\
\hline MMSE & $22.9 \pm 4.8$ & $25.1 \pm 4.1$ & $0.004 * *$ & $21.7 \pm 3.9$ & $24.2 \pm 4.3$ & $0.000 * * *$ \\
\hline $\mathrm{MoCA}$ & $16.3 \pm 6.1$ & $19.3 \pm 5.1$ & $0.003^{* *}$ & $15.4 \pm 5.4$ & $17.8 \pm 5.6$ & $0.006 * *$ \\
\hline DSF & $5.2 \pm 1.3$ & $5.4 \pm 1.4$ & 0.437 & $5.6 \pm 1.4$ & $5.6 \pm 1.1$ & 10.00 \\
\hline DSB & $2.9 \pm 1.2$ & $3.0 \pm 1.0$ & 0.635 & $3.1 \pm 1.1$ & $3.3 \pm 1.4$ & 0.625 \\
\hline TMT-A & $119.2 \pm 120.8$ & $56.4 \pm 72.1$ & $0.002 * *$ & $120.2 \pm 110.9$ & $95.1 \pm 113.3$ & $0.005 * *$ \\
\hline TMT-B & $185.2 \pm 120.7$ & $126.9 \pm 114.4$ & $0.016^{*}$ & $211.8 \pm 119.8$ & $184.0 \pm 130.7$ & $0.016^{*}$ \\
\hline SS & $8.6 \pm 9.4$ & $11.4 \pm 8.9$ & 0.064 & $6.2 \pm 7.1$ & $8.6 \pm 10.0$ & $0.023^{*}$ \\
\hline DSC & $17.2 \pm 17.5$ & $21.6 \pm 16.6$ & 0.082 & $17.2 \pm 19.1$ & $23.6 \pm 24.4$ & $0.002 * *$ \\
\hline SFT & $9.6 \pm 4.9$ & $11.9 \pm 4.8$ & $0.001^{* *}$ & $9.2 \pm 6.3$ & $10.6 \pm 6.5$ & 0.102 \\
\hline PFT & $3.3 \pm 3.2$ & $5.1 \pm 3.3$ & $0.004 * *$ & $5.0 \pm 4.7$ & $5.5 \pm 4.5$ & 0.221 \\
\hline
\end{tabular}

Data are given as mean $\pm \mathrm{SD}$.

Statistically significant difference: $* \mathrm{P}<0.05 * * \mathrm{P}<0.01 ; * * * \mathrm{P}<0.001$

MBI: modified Barthel Index; MMSE: mini-mental status examination; MoCA: Montreal Cognitive Assessment; DSF: digit span forward; DSB: digit span backward; TMT-A: trail making test-A; TMT-B: trail making test-B; SS: symbol search; DSC: digit symbol coding; SFT: semantic fluency test; PFT: phonemic fluency test. 


\section{COPYRIGHT $^{\circledR} 2021$ EDIZIONI MINERVA MEDICA}

TABLE IV.-Intergroup comparison of pre- to postintervention difference.

\begin{tabular}{lccc}
\hline Variables & $\begin{array}{c}\text { Therapist-driven cognitive } \\
\text { rehabilitation group } \\
(\mathrm{N} .=14)\end{array}$ & $\begin{array}{c}\text { Computerized cognitive } \\
\text { rehabilitation group } \\
(\mathrm{N} .=18)\end{array}$ & $\mathrm{P}$ \\
\hline MBI & $22.6 \pm 16.6$ & $16.6 \pm 13.4$ & 0.220 \\
MMSE & $2.3 \pm 2.5$ & $2.4 \pm 2.0$ & 0.842 \\
MoCA & $3.0 \pm 3.5 \pm$ & $2.3 \pm 3.2$ & 0.925 \\
DSF & $0.21 \pm 0.89$ & $0.00 \pm 0.97$ & 0.694 \\
DSB & $0.14 \pm 1.10$ & $0.17 \pm 0.92$ & 0.925 \\
TMT-A & $-62.79 \pm 101.18$ & $-27.61 \pm 36.61$ & 0.587 \\
TMT-B & $-58.36 \pm 103.49$ & $-34.89 \pm 80.95$ & 0.613 \\
SS & $2.79 \pm 8.00$ & $1.72 \pm 4.31$ & 0.955 \\
DSC & $4.36 \pm 14.36$ & $4.67 \pm 8.56$ & 0.319 \\
SFT & $2.29 \pm 2.13$ & $0.83 \pm 3.57$ & 0.189 \\
PFT & $1.86 \pm 1.96$ & $0.22 \pm 1.87$ & $0.013 *$ \\
\hline DFT & & &
\end{tabular}

Data are given as mean $\pm \mathrm{SD}$.

Statistically significant difference: $* \mathrm{P}<0.05$.

MBI: modified Barthel Index; MMSE: mini-mental status examination; MoCA: Montreal Cognitive Assessment; DSF: digit span forward; DSB: digit span backward; TMT-A: trail making test-A; TMT-B: trail making test-B; SS: symbol search; DSC: digit symbol coding; SFT: semantic fluency test; PFT: phonemic fluency test.

\section{Discussion}

The present study investigated and compared the efficacy of restorative TCR and CCR in restoring executive function in acute-to-subacute ABI patients. Our study results showed that both TCR and CCR significantly improved general cognitive function (MMSE, MoCA), selective attention and psychomotor speed (TMT-A, B), and performance in ADL (MBI). However, the two treatment methods showed different strengths in some cognitive domains. Only the CCR group showed significant improvements in the SS and DSC test results, while only the TCR group showed significant improvements in the COWAT (SFT and PFT) results. In the intergroup comparison, TCR was significantly more efficacious than CCR in improving PFT.

The COWAT is known to be a sensitive test for executive functions, including cognitive flexibility, strategy utilization, interference suppression, and response inhibition. ${ }^{11,52}$ Furthermore, the PFT is known to be more useful in assessing frontal lobe function, which is related to the switching of ideas, than is the SFT, which is more sensitive in assessing temporal lobe function. ${ }^{53}, 54$ Hence, we suppose that TCR accompanied by active assistance by trained therapists, including suggesting problem-solving strategies or providing goal-oriented encouragement in an interactive way, might be more effective in improving frontal lobe function. Especially for ABI patients with decreased autonomy in problem solving and strategy switch- ing, we suppose that more goal-oriented and constructive approaches are more helpful than repetitive, task-oriented, trial-and-error training. Moreover, considering that the SS and DSC results improved only in the CCR group, CCR might be more beneficial for improving psychomotor speed, visual perception, and working memory. 55,56 Performance in ADL, which was measured by the MBI, improved significantly after treatment in both groups. Since executive function is closely related to ADL performance, ${ }^{50}$ we suggest that this finding is the consequence of the improvement in executive function, as evidenced by the test results.

In previous studies, greater improvements due to TCR than due to CCR, as shown in our study, were rarely reported.24, 26, 28, 57 However, in some elaborate studies by Spikman et al. and Poulin et al., which utilized therapistdriven cognitive training methods on executive function, it was suggested that customized therapy is a better option than CCR for improving executive function and related ADL performance in ABI patients. ${ }^{33}, 58$ Considering the benefits of both TCR and CCR, De Luca et al. and Baltaduoneine et al. investigated the advantages of combining these methods in improving executive function in $\mathrm{ABI}$ patients. ${ }^{26,28}$

In the present study, we tried to distinguish the TCR and CCR treatment methods by modulating the interventions provided by the therapists. Although the TCR method used in our study is not exactly the same as those used in Spikman and Poulin's studies, interventions with trained therapists might have a positive impact on setting treatment goals and establishing problem-solving strategies for the patients.

Additional consideration is needed in interpreting our study results because the mean age of the participants in the present study $(64.7 \pm 15.2)$ was higher than that of participants from previous similar studies, who were most commonly in their 30's and 40's. ${ }^{21,22,27,28}$ According to research on smartphone ownership in 2018, Korea showed the highest prevalence among all global countries, with a prevalence of $95 \%$ in the overall population and nearly $80 \%$ in the group of individuals older than 60 years. ${ }^{59,} 60$ Due to this prevalence, the difficulty of using computerized apparatuses may be lower in elderly people in Korea than in other countries. However, considering that there have been reports of elderly participants who intended to refuse CCR due to unfamiliarity with interactive devices, ${ }^{26}$ the older mean age of the study population might have led to TCR being more efficacious than CCR. 


\section{COPYRIGHT $^{\circledR} 2021$ EDIZIONI MINERVA MEDICA}

\section{Strengths and limitations of the study}

One of the strengths of this study compared to most previous studies is that we included acute-to-subacute ABI patients specifically.21, 23-25, 27, 28, 32, 58 Although patients' cognitive function spontaneously recovers in this phase of ABI, we distinguished the difference in improving neurocognitive domains between the TCR and CCR groups. These findings showed that each cognitive rehabilitation method may impact on cognitive recovery differently in the acute-to-subacute rehabilitation period. Thus, this study might provide some evidence useful in choosing a cognitive rehabilitation method for ABI patients. ${ }^{15-17}$

Our study presents several limitations to consider. First, the sample size of our study was small, and a control group without an intervention was lacking. However, we thought that including a no-intervention group and preventing ABI patients in the acute-to-subacute phase from receiving cognitive therapy would be unethical. Additionally, we did not analyze the acute phase $(<2$ weeks after injury) and subacute phase patients sample separately because of the small size of the acute phase sample. Further studies with larger sample sizes should be conducted to determine whether the efficacy of two methods differs in the acute phase patients from subacute phase patients. Second, the treatment dose of intervention for both groups (10 times of 30-minute sessions) was relatively low compared to the one used in previous stud-

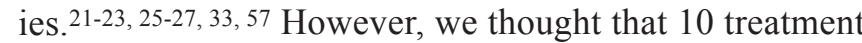
sessions lasting 30 minutes each would be enough for acute-to-subacute ABI patients with cognitive dysfunction, whose attention span may be short. Third, we did not evaluate long-term effects; thus, it was impossible to determine the sustained advantages of intensive training in the acute-to-subacute phase. Last, improvements in motor impairment could have influenced the improvements in ADL performance, as evaluated by the MBI, because the participants were in the acute-to-subacute ABI phase, which is when motor functions tend to improve considerably.

\section{Conclusions}

In conclusion, our study shows that TCR and CCR have distinct strengths in improving different domains of executive function in acute-to-subacute $\mathrm{ABI}$ patients and that TCR may be more effective in improving frontal lobe-related executive function.

\section{References}

1. Ma VY, Chan L, Carruthers KJ. Incidence, prevalence, costs, and impact on disability of common conditions requiring rehabilitation in the United States: stroke, spinal cord injury, traumatic brain injury, multiple sclerosis, osteoarthritis, rheumatoid arthritis, limb loss, and back pain. Arch Phys Med Rehabil 2014;95:986-995.e1.

2. Millis SR, Rosenthal M, Novack TA, Sherer M, Nick TG, Kreutzer JS, et al. Long-term neuropsychological outcome after traumatic brain injury. J Head Trauma Rehabil 2001;16:343-55.

3. Bogdanova Y, Yee MK, Ho VT, Cicerone KD. Computerized Cognitive Rehabilitation of Attention and Executive Function in Acquired Brain Injury: A Systematic Review. J Head Trauma Rehabil 2016;31:419-33.

4. Park YH, Jang JW, Park SY, Wang MJ, Lim JS, Baek MJ, et al. Executive function as a strong predictor of recovery from disability in patients with acute stroke: a preliminary study. J Stroke Cerebrovasc Dis 2015;24:554-61.

5. Kuo LM, Tsai WC, Chiu MJ, Tang LY, Lee HJ, Shyu YL. Cognitive dysfunction predicts worse health-related quality of life for older stroke survivors: a nationwide population-based survey in Taiwan. Aging Ment Health 2019;23:305-10.

6. Kramer JH, Reed BR, Mungas D, Weiner MW, Chui HC. Executive dysfunction in subcortical ischaemic vascular disease. J Neurol Neurosurg Psychiatry 2002;72:217-20.

7. Miyake A, Friedman NP, Emerson MJ, Witzki AH, Howerter A, Wager TD. The unity and diversity of executive functions and their contributions to complex "Frontal Lobe" tasks: a latent variable analysis. Cognit Psychol 2000;41:49-100.

8. Burgess PW, Simons JS. Theroies of frontal lobe executive function: clinical applications. In: Halligan PW, Wade DT, editors. The effectiveness of rehabilitation for cognitive deficits. Oxford: Oxford University Press; 2005.

9. Sachdev PS, Blacker D, Blazer DG, Ganguli M, Jeste DV, Paulsen JS, et al. Classifying neurocognitive disorders: the DSM-5 approach. Nat Rev Neurol 2014;10:634-42.

10. Fasotti L, Spikman JM. Cognitive rehabilitation of central executive disorders. In: Brouwer WH, van Zomeren AH, Berg IJ, Bouma JM, De Haan EH, editors. Cognitive rehabilitation of central executive disorders. Amsterdam: Boom; 2002.

11. Chung CS, Pollock A, Campbell T, Durward BR, Hagen S. Cognitive rehabilitation for executive dysfunction in adults with stroke or other adult non-progressive acquired brain damage. Cochrane Database Syst Rev 2013;CD008391.

12. Desmond DW, Moroney JT, Sano M, Stern Y. Recovery of cognitive function after stroke. Stroke 1996;27:1798-803.

13. Tham W, Auchus AP, Thong M, Goh ML, Chang HM, Wong MC, et al. Progression of cognitive impairment after stroke: one year results from a longitudinal study of Singaporean stroke patients. J Neurol Sci 2002;203-204:49-52.

14. Pedersen PM, Jørgensen HS, Nakayama H, Raaschou HO, Olsen TS. Aphasia in acute stroke: incidence, determinants, and recovery. Ann Neurol 1995;38:659-66.

15. Baltaduoniene D, Kubilius R, Mingalia S. Computer - based cognitive rehabilitation for cognitive functions after stroke. Czech and Slovak Neurology and Neurosurgery. 2018;81:269-77.

16. Park JH, Park JH. The effects of a Korean computer-based cognitive rehabilitation program on cognitive function and visual perception ability of patients with acute stroke. J Phys Ther Sci 2015;27:2577-9.

17. Zucchella C, Capone A, Codella V, Vecchione C, Buccino G, Sandrini $\mathrm{G}$, et al. Assessing and restoring cognitive functions early after stroke. Funct Neurol 2014;29:255-62.

18. Fuchs TA, Ziccardi S, Dwyer MG, Charvet LE, Bartnik A, Campbell $\mathrm{R}$, et al. Response heterogeneity to home-based restorative cognitive re- 


\section{COPYRIGHT $^{(\odot)} 2021$ EDIZIONI MINERVA MEDICA}

habilitation in multiple sclerosis: an exploratory study. Mult Scler Relat Disord 2019;34:103-11.

19. Merzenich MM, Van Vleet TM, Nahum M. Brain plasticity-based therapeutics. Front Hum Neurosci 2014;8:385.

20. Vinogradov S, Fisher M, de Villers-Sidani E. Cognitive training for impaired neural systems in neuropsychiatric illness. Neuropsychopharmacology 2012;37:43-76.

21. De Luca R, Calabrò RS, Gervasi G, De Salvo S, Bonanno L, Corallo $\mathrm{F}$, et al. Is computer-assisted training effective in improving rehabilitative outcomes after brain injury? A case-control hospital-based study. Disabil Health J 2014;7:356-60.

22. Fernández E, Bringas ML, Salazar S, Rodríguez D, García ME, Torres M. Clinical impact of RehaCom software for cognitive rehabilitation of patients with acquired brain injury. MEDICC Rev 2012;14:32-5.

23. Veisi-Pirkoohi S, Hassani-Abharian $P$, Kazemi R, Vaseghi S, Zarrindast MR, Nasehi M. Efficacy of RehaCom cognitive rehabilitation software in activities of daily living, attention and response control in chronic stroke patients. J Clin Neurosci 2020;71:101-7.

24. Chen SH, Thomas JD, Glueckauf RL, Bracy OL. The effectiveness of computer-assisted cognitive rehabilitation for persons with traumatic brain injury. Brain Inj 1997;11:197-209.

25. Nyberg CK, Nordvik JE, Becker F, Rohani DA, Sederevicius D, Fjell AM, et al. A longitudinal study of computerized cognitive training in stroke patients - effects on cognitive function and white matter. Top Stroke Rehabil 2018;25:241-7.

26. Baltaduonienė D, Kubilius R, Berškienė K, Vitkus L, Petruševičienė D. Change of Cognitive Functions after Stroke with Rehabilitation Systems. Transl Neurosci 2019;10:118-24.

27. Lundqvist A, Grundström K, Samuelsson K, Rönnberg J. Computerized training of working memory in a group of patients suffering from acquired brain injury. Brain Inj 2010;24:1173-83.

28. De Luca R, Leonardi S, Spadaro L, Russo M, Aragona B, Torrisi M, et al. Improving Cognitive Function in Patients with Stroke: Can Computerized Training Be the Future? J Stroke Cerebrovasc Dis 2018;27:1055-60. 29. Pantzartzidou A, Dionyssiotis Y, Stefas E, Samlidi E, Giorgiadis T, Kandylakis E. Rehacom software application is effective in cognitive rehabilitation of patients with brain injuries. Phys Med Rehabil Res 2017;2:1-4.

30. Anguera JA, Boccanfuso J, Rintoul JL, Al-Hashimi O, Faraji F, Janowich $\mathrm{J}$, et al. Video game training enhances cognitive control in older adults. Nature 2013;501:97-101.

31. Owen AM, Hampshire A, Grahn JA, Stenton R, Dajani S, Burns AS, et al. Putting brain training to the test. Nature 2010;465:775-8.

32. Yeh TT, Chang KC, Wu CY. The Active Ingredient of Cognitive Restoration: A Multicenter Randomized Controlled Trial of Sequential Combination of Aerobic Exercise and Computer-Based Cognitive Training in Stroke Survivors With Cognitive Decline. Arch Phys Med Rehabil 2019;100:821-7.

33. Poulin V, Korner-Bitensky N, Bherer L, Lussier M, Dawson DR. Comparison of two cognitive interventions for adults experiencing executive dysfunction post-stroke: a pilot study. Disabil Rehabil 2017;39:1-13. 34. Poulin V, Korner-Bitensky N, Dawson DR, Bherer L. Efficacy of executive function interventions after stroke: a systematic review. Top Stroke Rehabil 2012;19:158-71.

35. van de Ven RM, Murre JM, Veltman DJ, Schmand BA. ComputerBased Cognitive Training for Executive Functions after Stroke: A Systematic Review. Front Hum Neurosci 2016;10:150.

36. Kim DY, Kim YH, Lee J, Chang WH, Kim MW, Pyun SB, et al. Clinical practice guideline for stroke rehabilitation in Korea 2016. Brain

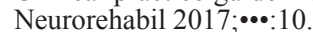

37. Hebert D, Lindsay MP, McIntyre A, Kirton A, Rumney PG, Bagg S, et al. Canadian stroke best practice recommendations: stroke rehabilitation practice guidelines, update 2015. Int J Stroke 2016;11:459-84.

38. Winstein CJ, Stein J, Arena R, Bates B, Cherney LR, Cramer SC, et al.; American Heart Association Stroke Council, Council on Cardiovas- cular and Stroke Nursing, Council on Clinical Cardiology, and Council on Quality of Care and Outcomes Research. Guidelines for adult stroke rehabilitation and recovery: a guideline for healthcare professionals from the American Heart Association/American Stroke Association. Stroke 2016;47:e98-169.

39. Okkema K. Cognition and Perception in the Stroke Patient: A Guide to Functional Outcomes in Occupational Therapy. Aspen, CO: Aspen Publishers Inc.; 1993.

40. Tsaousides T, Gordon WA. Cognitive rehabilitation following traumatic brain injury: assessment to treatment. Mt Sinai J Med 2009;76:173-81.

41. Rohling ML, Faust ME, Beverly B, Demakis G. Effectiveness of cognitive rehabilitation following acquired brain injury: a meta-analytic re-examination of Cicerone et al.'s $(2000,2005)$ systematic reviews. Neuropsychology 2009;23:20-39.

42. Salazar AM, Warden DL, Schwab K, Spector J, Braverman S, Walter J, et al.; Defense and Veterans Head Injury Program (DVHIP) Study Group. Cognitive rehabilitation for traumatic brain injury: A randomized trial. JAMA 2000;283:3075-81.

43. Smith A. Symbol Digit Modalities Test (SDMT) Manual. Los Angeles, CA: Western Psychological Services; 1982.

44. Reitan R. Halstead-Reitan neuropsychological test battery: theory and clinical interpretation. Tucson, AZ: Reitan Neuropsychology; 1985.

45. Wechsler D. Wechsler memory scale (WMS-III). Chicago, IL: Psychological Corporation; 1997.

46. Eramudugolla R, Mortby ME, Sachdev P, Meslin C, Kumar R, Anstey KJ. Evaluation of a research diagnostic algorithm for DSM-5 neurocognitive disorders in a population-based cohort of older adults. Alzheimers Res Ther 2017;9:15.

47. Parker DM, Crawford JR. A handbook of neuropsychological assessment. Crawford JR, Parker DM, Mckinlay WM, editors. Hove: Lawrence Erlbaum Associates Ltd.; 1992.

48. Stuss DT, Alexander MP, Hamer L, Palumbo C, Dempster R, Binns $\mathrm{M}$, et al. The effects of focal anterior and posterior brain lesions on verbal fluency. J Int Neuropsychol Soc 1998;4:265-78.

49. Nys GM, van Zandvoort MJ, de Kort PL, Jansen BP, Kappelle LJ, de Haan EH. Restrictions of the Mini-Mental State Examination in acute stroke. Arch Clin Neuropsychol 2005;20:623-9.

50. Lim KB, Kim J, Lee HJ, Yoo J, You EC, Kang J. Correlation Between Montreal Cognitive Assessment and Functional Outcome in Subacute Stroke Patients With Cognitive Dysfunction. Ann Rehabil Med 2018;42:26-34.

51. Abwender DA, Swan JG, Bowerman JT, Connolly SW. Qualitative analysis of verbal fluency output: review and comparison of several scoring methods. Assessment 2001;8:323-38.

52. Perret E. The left frontal lobe of man and the suppression of habitual responses in verbal categorical behaviour. Neuropsychologia 1974;12:323-30.

53. Troyer AK, Moscovitch M, Winocur G. Clustering and switching as two components of verbal fluency: evidence from younger and older healthy adults. Neuropsychology 1997;11:138-46.

54. Lim KB, Kim J, Lee HJ, Yoo J, Kim HS, Kim C, et al. COWAT Performance of Persons with Alzheimer Dementia, Vascular Dementia, and Parkinson Disease Dementia According to Stage of Cognitive Impairment. PM R 2019;11:737-44.

55. Joy S, Kaplan E, Fein D. Digit Symbol-Incidental Learning in the WAIS-III: construct validity and clinical significance. Clin Neuropsychol 2003;17:182-94.

56. Liebel SW, Clark US, Xu X, Riskin-Jones HH, Hawkshead BE, Schwarz NF, et al. An FMRI-compatible Symbol Search task. J Int Neuropsychol Soc 2015;21:231-8.

57. Fernandez E, Bergado Rosado JA, Rodriguez Perez D, Salazar Santana S, Torres Aguilar M, Bringas ML. Effectiveness of a Computer-Based Training Program of Attention and Memory in Patients with Acquired Brain Damage. Behav Sci (Basel) 2017;8:E4. 


\section{COPYRIGHT $^{\circledR} 2021$ EDIZIONI MINERVA MEDICA}

58. Spikman JM, Boelen DH, Lamberts KF, Brouwer WH, Fasotti L. Effects of a multifaceted treatment program for executive dysfunction after acquired brain injury on indications of executive functioning in daily life. J Int Neuropsychol Soc 2010;16:118-29.

59. Silver L. Smartphone ownership is growing rapidly around the world, but not always equally. Pew Research Center; 2019 [Internet]. Avail- able from: https://www.pewresearch.org/global/2019/02/05/smartphoneownership-is-growing-rapidly-around-the-world-but-not-always-equally/ [cited 2021, Jan 22].

60. Gallup 2012-2018: smartphone usage rate. Gallup; 2018 [Internet]. Available from: https://www.gallup.co.kr/gallupdb/reportContent. asp?seqNo=943. [cited 2021, Jan 22].

Conflicts of interest.- The authors certify that there is no conflict of interest with any financial organization regarding the material discussed in the manuscript. Authors' contributions.- Jiyong Kim has given substantial contributions to manuscript design and supervision, Ha S. Kim to statistical analysis and manuscript writimg, Kil-Byung Lim and Yong W. Kim to manuscript conception, Jeehyun Yoo, Changgyu Kim, Sang W. Lee, and Sungsik Son to data acquisition, analysis and interpretation, Jiyong Kim and Yong W. Kim to manuscript critical revision. All authors read and approved the final version of the manuscript. History.-Article first published online: January 15, 2021. - Manuscript accepted: January 8, 2021. - Manuscript revised: December 21, 2020. - Manuscript received: July 20, 2020 